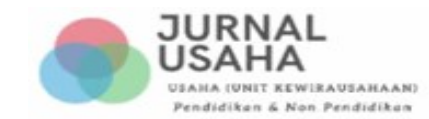

Vol 1, No. 1 (2020), June 2020

E-ISSN: 2746-2471

\title{
PENERAPAN NORMA PERHITUNGAN PAJAK NETTO BAGI WAJIB PAJAK ORANG PRIBADI PADA WILAYAH KERJA KANTOR PAJAK PRATAMA PASAR MINGGU
}

\author{
Deddy Dariansyah S. \\ Universitas Indraprasta PGRI \\ deddyjogjazz@yahoo.co.id
}

\begin{abstract}
ABSTRAK
Peneliti ingin mengetahui apakah Wajib Orang Pribadi bergerak dibidang UMKM sudah menerapkan Peraturan Direktur Jenderal Pajak Nomor PER-17/PJ/2015 tentang Norma Penghitungan Penghasilan Neto terhadap beberapa pekerja bebas tertentu, pada wilayah kerja Kantor Pelayanan Pajak Pasar Minggu. Dalam penelitian ini membahas mengenai Norma Penghitungan Penghasilan Neto terhadap terhadap Wajib Orang Pribadi mempunyai usaha sektor UMKM. Metode penelitian yang digunakan dalam penelitian ini berbentuk penelitian yuridis normatif dengan tipe penelitian deskriptif analitis. Pada penerapan Peraturan Direktur Jenderal Pajak PER17/PJ/2015 tentang Norma Penghitungan Penghasilan Neto terdapat dua permasalahan yaitu perbedaan interpretasi peraturan antara Direktorat Jenderal Pajak dan Wajib Pajak itu sendiri sehingga masih terdapat adanya ketidaktahuan wajib pajak terhadap peraturan tersebut. Hasil penelitian ini bahwa wajib Pajak sudah menerapkan pengaturan mengenai Norma Penghitungan Penghasilan Neto PER17/PJ/2015 sesuai Klasifikasi Lapangan Usaha (KLU) masing-masing.
\end{abstract}

Kata Kunci: Peraturan Pajak, Norma Perhitungan, Wajib Pajak 
E-ISSN: 2746-2471

\section{A. PENDAHULUAN}

Berdasarkan laporan Kementerian Keuangan untuk Anggaran Pendapatan Belanja Negara (APBN) 2019, dari pemerintah menetapkan target penerimaan Pajak non- Migas adalah Rp. 1.786,4 trilyun, Dengan perluasan dasar perhitungan tersebut, pemerintah mengusulkan rasio penerimaan Pajak (Tax Ratio) dalam Rancangan Anggaran Pendapatan dan Belanja Negara Perubahan (APBN) 2019. Dengan semakin meningkatnya target penerimaan negara dari sektor pajak pada struktur APBN dari tahun ke tahun, yang besarnya rasio penerimaan sektor pajak terhadap total penerimaan dalam negeri berkisar 78\% . untuk di tahun 2019 ini. Berikut ini Tabel Target Penerimaan Pajak selama 5 tahun dari Tahun 2016 sampai dengan 2019 dari Direktorat Jendral Pajak berdasarkan APBN adalah sebagai berikut:

\begin{tabular}{|c|c|c|}
\hline No & Tahun Penerimaan Pajak & Jumlah Target Penerimaan \\
\hline 1 & 2015 & $\mathrm{Rp} 1.294$ triliun \\
\hline 2 & 2016 & $\mathrm{Rp} 1.335 .3$ triliun \\
\hline 3 & 2017 & $\mathrm{Rp} 1.339,6$ triliun \\
\hline 4 & 2018 & $\mathrm{Rp} 1.521,5$ trilyun \\
\hline 5 & 2019 & $\mathrm{Rp} 1.786,4$ trilyun \\
\hline
\end{tabular}

Dari tabel di atas terlihat sangat jelas bahwa setiap tahunnya target penerimaan meningkat jumlah nya, berdasarkan Anggaran Pendapatan Belanja Negara (APBN) Tahun 2019. Hal ini diperlukan langkah-langkah strategis dan tepat oleh Direktorat Jendral Pajak sebagai institusi pengumpul penerimaan negara di Indonesia, agar rencana penerimaan pajak dapat tercapai, dari Pihak Direktorat Jendral Pajak menjalankan Program Ekstensifikasi dan Intensikasi, Untuk ini diperlukan peran aktif dari masyarakat beperan serta dalam membayar pajak untuk membiayai pembangunan di Indonesia. sistem pemungutan pajak yang berlaku saat ini adalah Self Assessment System. Tujuan diberlakukannya sistem ini agar masyarakat memiliki kesadaran untuk memenuhi kewajiban di bidang perpajakannya. Oleh karena itu wajib pajak harus mengetahui segala hak dan kewajibannya dengan baik dan benar seperti, bagaimana cara menghitung, melaporkan serta menyetorkan pajak terutangnya, bagaimana mengajukan keberatan dan banding, bagaimana mengajukan restitusi (pengembalian) pajak, dan lain-lain. Dalam hal ini penulis sangat tertarik akan membahas penerapan Norma Perhitungan Pajak Netto bagi Wajib Pajak Pribadi yang mempunyai usaha pada wilayah kerja Kantor Pelayanan Pajak Pratama Pasar Minggu.

\section{B. KAJIAN PUSTAKA}

Pajak berasal dari (dari bahasa Latin taxo; "rate") adalah iuran rakyat kepada negara berdasarkan undang-undang, sehingga dapat dipaksakan, dengan 


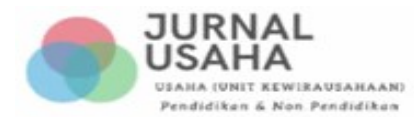

Vol 1, No. 1 (2020), June 2020

E-ISSN: 2746-2471

tidak mendapat balas jasa secara langsung. Sedangkan definisi Pajak menurut Undang Undang Nomor 16 tahun 2009 tentang perubahan tentang Ketentuan Umum dan Tata cara Perpajakan, Wajib Pajak adalah kontribusi wajib kepada negara yang terutang oleh pribadi atau badan yang bersifat memaksa berdasarkan Undang Undang, dengan tidak mendapatkan imbalan secara langsung dan digunakan untuk keperluan negara bagi sebesar besarnya untuk kemakmuran rakyat. Sedangkan menurut pasal 14 Undang Undang nomor 36 tahun 2008 tentang pajak penghasilan terdapat pengaturan mengenai Norma perhitungan Penghasilan Neto. Dalam penjelasannya, norma perhitungan penghasilan neto adalah salah satu metode untuk menentukan besarnya penghasilan neto yang selanjutnya akan digunakan untuk menghitung besarnya pajak penghasilan yang terutang dan harus dibayaar oleh Wajib pajak. Norma Perhitungan Penghasilan Neto dibuat dan disempurkan oleh Direktorat Jendral Pajak dengan peraturan Direktur Jendral Pajak nomor PER-17/PJ/2015 tentang norma perhitungan penghasilan neto. dalam penerapan norma perhitungan penghasilan neto bagi Wajib Pajak dengan syarat sebagai berikut:

1. Wajib Pajak dalam negeri Orang Pribadi

2. Memperoleh peredaran bruto tidak melebihi Rp 4.800.000.000 dalam satu tahun

3. Penghasilan tersebut berasal dari pekerjaan bebas

4. Wajib Pajak harus memberitahukan kepada Direktur Jendral pajak dalam jangka waktu 3 bulan pertama dari tahun pajak yang bersasngkutan

5. Wajib Pajak menyelenggarakan pencatatan tentang peredaran brutonya sebagaimna diatur dalam Undang Undang yang mengtur mengenai ketentuan Umum dan Tata cara perpajakan.

Dalam ini jika Wajib Pajak mempunyai usaha terlebh dahulu menghitung norma pajak penghasilan neto setelah itu dalam membuat laporan Keuangan disusun berdasarkan berdasarkan prinsip yang berlaku umum, yaitu Standar Akutansi Keuangan (SAK), sedangkan untuk kepentingan fiskal, Laporan Keuangan disusun berdasarkan Peraturan Perpajakan (Undang Undang Pajak Penghasilan). Untuk mengatasi perbedaan tersebut digunakan beberapa pendekatan dalam penyusunan laporan keuangan fiskal, yaitu:

1. Laporan Keuangan fiskal disusun secara beriringan dengan laporan keuangan komersial, artinya meskipun laporan keuangan komersial atau bisnis disusun berdasarkan prinsip akutansi bisnis, tetapi ketentuan perpajakan sangat dominan dalam mendasari proses penyusunan laporan keuangan.

2. Laporan keuangan fiskal disusun dengan menyisipkan ketentuan ketentuan pajak dalam laporan keuangan bisnis, artinya pembukuan yang diselenggarakan perusahaan didasarkan perusahaan didasarkan pada prinsip akutansi bisnis, tetapi 


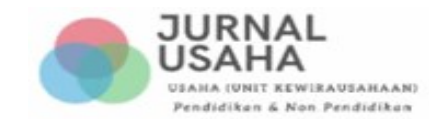

Vol 1, No. 1 (2020), June 2020

E-ISSN: 2746-2471

jika ada ketentuan perpajakan yang tidak sesuai dengan prisnip akautansi bisnis maka diprioritaskan adalah ketentuan Perpajakan.

Untuk menjembatani adanya perbedaan dalam laporan keuangan komersial dan laporan keuangan fiskal agar lebih efesiensi maka Laporan Keuangan fiskal disusun secara beriringan dengan laporan keuangan komersial, artinya meskipun laporan keuangan komersial atau bisnis disusun berdasarkan prinsip akutansi bisnis, tetapi ketentuan perpajakan sangat dominan dalam mendasari proses penyusunan laporan keuangan. Penyebab perbedaan laporan keuangan komersial dan laporan keuangan fiskal adalah karena terdapat perbedaan prinsip akutansi, metode dan prosedur akutansi, perbedaan pengakuan penghasilan dan biaya, serta perbedaan perlakuan penghasilan dan biaya. Dalam menyikapi perbedaan-perbedaan yang terjadi antara Laporan Keuangan Laba Rugi Komersial dan Laba Rugi Fiskal, berdasarkan Standar Akuntansi Keuangan dan serta Undang-Undang perpajakan yang berlaku, atas dasar inilah penulis ingin meneliti untuk menganalisa Penerapan Norma Perhitngan Pajak Netto bagi Wajib Pajak Orang Pribadi pada wilayah kerja Kantor Pajak Pratama Pasar Minggu

\section{METODE PENELITIAN}

Metode penelitian ini menggunakan pendekatan Deskriptif Kualitatif, dalam penelitian ini bersifat Deskriptif Kualitiatif yaitu mendeskripsikan tentang Rekonsiliasi Fiskal atas Laporan Keuangan komersial, serta mengumpulkan sejumlah data data pendukung untuk mendapatkan gambaran fakta-fakta yang jelas tentang hal keadaan Laporan Keuangan Tahun 2019 atas usaha UMKM Wajib Pajak Orang Pribadi tersebut. Pengertian Metode deskriptif Sugiyono (2013) adalah Metode deskriptif adalah metode yang digunakan untuk menggambarkan atau menganalisis suatu hasil penelitian tetapi tidak digunakan untuk membuat kesimpulan yang lebih luas. Sedangkan menurut Sugiyono (2013) Metode penelitian kuantitatif dapat diartikan sebagai metode penelitian yang berlandaskan pada filsafat positivisme, digunakan untuk meneliti pada populasi atau sampel tertentu. Teknik pengambilan sampel pada umumnya dilakukan secara random, pengumpulan data menggunakan instrumen penelitian, analisis data bersifat kuantitatif/statistik dengan tujuan untuk menguji hipotesis yang telah ditetapkan.

Metode Pengumpulan Data yaitu pengumpulan data dilakukan untuk memperoleh informasi yang dibutuhkan dalam rangka mencapai tujuan.Dalam proses pengumpulan data yang diperlukan, penulis menggunakan 2 (dua) teknik pengumpulan data yaitu;

1. Interview, yaitu mengadakan wawancara dalam hal ini tanya jawab dengan Wajib Pajak yang ditujukan untuk mengadakan penelitian terhadap tata cara pelaporan yang menyangkut masalah tersebut.

2. Dokumenter, cara pengumpulan data dengan menggunakan arsip dan dokumendokumen laporan keuangan dari Wajib Pajak Orang Pribadi yang bersangkutan.

Metode Analisis yang digunakan penulis dalam menyelesaikan permasalahan dalam penelitian ini adalah dengan menggunakan analisis deskriptif kualitatif. Proses 


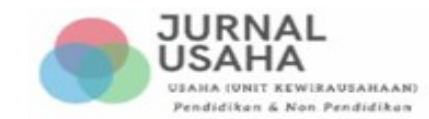

Vol 1, No. 1 (2020), June 2020

E-ISSN: 2746-2471

analisis merupakan proses awal dalam tahap perencanaan penyelesaian suatu masalah, di dalam penelitian ini, penulis akan mempelajari Laporan Keuangan yang diperoleh dari Wajib Pajak Orang Pribadi kemudian dianalisa apakah proses rekonsiliasi fiskal yang dibuat tersebut sudah benar dan telah sesuai dengan peraturan Pajak yang berlaku di Indonesia saat ini. Sebagai contoh seorang Wajib Pajak Pribadi mempunyai usaha retail yang telah terdaftar pada Kantor Pratama Pajak Pasar Minggu, dengan status menikah dengan mempunyai istri dan anak 1 orang $(\mathrm{K} / 1)$

\section{HASIL DAN PEMBAHASAN}

Dalam penelitian dan pembahasan ini untuk menerapkan Norma perhitungan penghasilan neto bagi Wajib Pajak yang mempunyai usaha dalam membuat laporan keuangan diperlukan Rekonsiliasi fiskal dilakukan berdasarkan dari laporan laba rugi komersial yang disusun Laba (rugi) komersial tersebut dilakukan koreksi fiskal sehingga menghasilkan laba (rugi) fiskal atau sering disebut penghasilan neto fiskal. Dalam melakukan koreksi fiskal yang akan dikoreksi adalah laporan Laba rugi komersial yang dibuat oleh perusahaan berdasarkan standar akuntansi yang berlaku, untuk dilakukan Rekonsiliasi fiskal berdasarkan peraturan perpajakan yang berlaku saat ini. Dimana penelitian akan dilakukan pada Laporan laba rugi komersial yang dibuat oleh Wajib Pajak Orang Pribadi yang mempunyai usaha berdasarkan standar akuntansi. Berikut ini yang akan menjadi fokus penelitian untuk analisis laporan keungan Wajib Pajak Orang Pribadi yang mempunyai usaha hal ini sangat diperlukan terlebih dahulu perhitungan norma penghasilan pajak neto setelah itu membuat laporan rekonsiliasi fiskal pada laporan laba-rugi periode 1 Januari - 31 Desember 2019 sebagai berikut:

Berikut ini Daftar Laporan Keuangan Tahun 2019

1. Penjualan Rp 7.500 .000 .000

Retur Penjualan $\quad$ Rp 200.000.000

Penjualan Neto Rp 7.300.000.000

2. HPP

Rp 6.100.000.000

3. Laba bruto usaha

Rp 1.200.000.000

4. beban umum pengusaha dan pengeluaran lainnya:

a. gaji, tunjangan, dan lain lain $\quad \operatorname{Rp} 300.000 .000$

b. PPH 21

Rp 20.000 .000 
Vol 1, No. 1 (2020), June 2020

E-ISSN: 2746-2471

c. premi asuransi kebakaran $\quad \mathrm{Rp} 60.000 .000$

d. premi asuransi kesehatan $\quad$ Rp 45.000.000

e. premi asuransi jiwa $\quad \mathrm{Rp} 30.000 .000$

f. biaya listrik dan telepon $\quad$ Rp 110.000.000

g. biaya ATK Rp 55.000 .000

h biaya perjalanan $\quad$ Rp 75.000.000

I biaya pemeliharaan $\quad \mathrm{Rp} 35.000 .000$

$\mathrm{J}$ bunga pinjaman usaha $\quad \mathrm{Rp} 25.000 .000$

K penyusutan $\quad \mathrm{Rp} 65.000 .000$

L pembayaran pajak $\quad \mathrm{Rp} \mathrm{25.000.000}$

Jumlah beban perusahaa $\quad$ Rp 845.000.000

5. laba neto $\quad$ Rp 355.000.000

Keterangan:

1. Premi asuransi kebakaran terdiri asuransi kebakaran bangunan kantor Rp 50.000.000 dan asuransi kebakaran rumah Rp 10.000.000

2. Premi asuransi kesehatan utk karyawan $\mathrm{Rp} 35.000 .000$ dan asuransi kesehatan utk anak dan istri $\operatorname{Rp} 35.000 .000$

3. Premi asuransi jiwa utk karyawan Rp 25.000.000 dan asuransi jiwa utk anak dan istri $\operatorname{Rp} 5.000 .000$

4. Listrik dan telepon utk kantor sebesar $\mathrm{Rp}$ 85.000.000, listrik dan telepon utk rumah pribadi $\mathrm{Rp} 25.000 .000$

5. Penyusutan komersial sebesar Rp 65.000.000,- dan perhitungan penyusutan sesuai dengan UU PPH Rp 55.000.000 +++

6. Rincian biaya pajak dan restribusi yaitu pengeluaran utk Angsuran bulanan PPH 25 thn pajak 2019 Rp 10.000.000,- 


\section{JURNAL}

Vol 1, No. 1 (2020), June 2020

E-ISSN: 2746-2471

PBB kantor Rp 5.000.000

PBB rumah Rp 2.500.000

Pajak kendaraan bermotor Rp 5.000.000

Restribusi daerah perusahaan $\mathrm{Rp} 2.500 .000$

7. Penghasilan lainnya
a. Deviden dari PT ABC Rp 100.000.000
b. Bunga deposito Rp 5.000 .000
c. Hadiah undian berupa mobil Rp 200.000.000

8. Penghasilan istri

Penghasilan Bruto $\quad$ Rp 238.800.000

Penghasilan Neto $\quad$ Rp 231.600.000

PPH 21 pemotong PT selaras NPWP 01.679.888.8323.000 Rp 26.968.000 (istri tdk mempunyai NPWP dan ikut NPWP suami )

Daftar Harta

\begin{tabular}{|c|l|l|l|l|}
\hline NO & Jenis harta & $\begin{array}{l}\text { Tahun } \\
\text { perolehan }\end{array}$ & $\begin{array}{l}\text { Harga perolehan } \\
\text { Rp }\end{array}$ & Keterangan \\
\hline 1 & Bangunan & 2013 & 1.000 .000 .000 & \\
\hline 2 & Saham & 2018 & 1.000 .000 .000 & \\
\hline 3 & $\begin{array}{l}\text { Bangunan } \\
\text { kantor }\end{array}$ & 2015 & 1.500 .000 .000 & \\
\hline 4 & Deposito & 2016 & 100.000 .000 & \\
\hline 5 & Sedan & 2017 & 250.000 .000 & \\
\hline 6 & $\begin{array}{l}\text { Perabot Rumah } \\
\text { Tangga }\end{array}$ & 2018 & 300.000 .000 & \\
\hline
\end{tabular}

Sumber Wajib Pajak Orang Pribadi

Pemecahan masalah ( kertas kerja )

\section{Jawaban}


Vol 1, No. 1 (2020), June 2020

E-ISSN: 2746-2471

\begin{tabular}{|l|l|l|l|l|}
\hline Pos / rekening & Komersial & Koreksi + & Koreksi - & FISKAL \\
\hline Penjualan & 7.500 .000 .000 & & & 7.500 .000 .000 \\
\hline Retur penjualan & 200.000 .000 & & & 200.000 .000 \\
\hline Penjualan neto & 7.300 .000 .000 & & & 7.300 .000 .000 \\
\hline HPP & 6.100 .000 .000 & & & 6.100 .000 .000 \\
\hline Laba bruto & 1.200 .000 .000 & & 1.200 .000 .000 \\
\hline $\begin{array}{l}\text { Gaji, tunjangan } \\
\text { dll }\end{array}$ & 300.000 .000 & & 300.000 .000 \\
\hline PPH 21 & 20.000 .000 & 20.000 .000 & & 0 \\
\hline $\begin{array}{l}\text { Premi asuransi } \\
\text { kebakaran }\end{array}$ & 60.000 .000 & 10.000 .000 & & 50.000 .000 \\
\hline $\begin{array}{l}\text { Premi asuransi } \\
\text { kesehatan }\end{array}$ & 45.000 .000 & 10.000 .000 & & 35.000 .000 \\
\hline $\begin{array}{l}\text { Premi asuransi } \\
\text { jiwa }\end{array}$ & 30.000 .000 & 5.000 .000 & & 25.000 .000 \\
\hline Listrik dan telp & 110.000 .000 & 25.000 .000 & & 85.000 .000 \\
\hline ATK & 55.000 .000 & & & 55.000 .000 \\
\hline $\begin{array}{l}\text { Biaya } \\
\text { perjalanan }\end{array}$ & 75.000 .000 & & & 75.000 .000 \\
\hline $\begin{array}{l}\text { Biaya } \\
\text { pemeliharaan }\end{array}$ & 35.000 .000 & & & 35.000 .000 \\
\hline $\begin{array}{l}\text { Bunga } \\
\text { pinjaman usaha }\end{array}$ & 25.000 .000 & & & \\
\hline Penyusutan \\
\hline $\begin{array}{l}\text { Pembayaran } \\
\text { pajak }\end{array}$ & 25.000 .000 & 12.500 .000 & & \\
\hline $\begin{array}{l}\text { Penghasilan } \\
\text { neto usaha }\end{array}$ & 355.000 .000 & 92.500 .000 & & \\
\hline
\end{tabular}


Vol 1, No. 1 (2020), June 2020

E-ISSN: 2746-2471

Penjelasan koreksi fiskal

a. PPH 21 bukan merupakan biaya fiskal sesuai pasal 9 ( 1)

b. Premi asuransi kebakaran rumah pribadi bukan merupakan biaya fiskal karena tidak terkait usaha dan juga utk kepentingan pribadi pasal 9 ( 1)

c. Premi asuransi kesehatan dan jiwa karyawan merupakan biaya fiskal sepanjang dimasukan sbg objek PPH 21 sesuai pasal 9 ( 1)

d. Premi asuransi dan jiwa anak merupakan bukan biaya fiskal

e. Listrik dan telp utk rumah bukan merupakan biaya fiskal

f. Penyusutan dilakukan koreksi karena penyusutan komersial lebih besar dibandingkan penyusutan menurut pasal 11

g. $\quad$ BB rumah dan pajak kendaraan bermotor atas nama individu bukan merupakan biaya

h. PPH 25 bukan merupakan biaya fiskal

i. Deviden PT ABC sebesar Rp 100.000.000. deviden yg diterima oleh orag pribadi dikenakan PPH final sebesar $10 \%$ atau Rp 10.000.000. pajak tersebut seharusnya dipotong oleh PT ABC sehingga bukti pembayaran pajak berupa potong dari PT ABC. Apabila tdk potong PPH FINAL sebesar $20 \%$ atau Rp 20.000 .000

j. $\quad$ Bunga deposito sebesar Rp 5.000.000 bunga deposito dan tabungan lainnya oleh perbankan dipotong PPH final $20 \%$ atau Rp 1.000.000

k. Hadiah undian berupa mobil sebesar Rp 200.000.000 pajak undian dibayar pada saat penerimaan hadiah sebesar $25 \%$ atau Rp 50.000.000

Perhitungn neto suami digabung dengan penghasilan neto istri karena istri tidak mempunyai NPWP. Sehingga kewajiban pajak nya di gabung dengan suami.

Penghasilan neto suami Rp 447.500.000

Penghasilan neto istri

Rp 231.600.000

Jumlah penghasilan neto

Rp 679.100.000

$\operatorname{PTKP}(\mathrm{K} / 1)$

Rp 34.320.000 


\begin{tabular}{|c|c|}
\hline $\begin{array}{l}\text { Vol 1, No. } 1 \text { (2020), June } 2020 \\
\text { E-ISSN: } 2746-2471\end{array}$ & \\
\hline $\begin{array}{l}\text { PKP } \\
\text { PPh terutang } \\
5 \% \times \operatorname{Rp} 50.000 .000,^{-} \\
15 \% \times \operatorname{Rp} 200.000 .000=\operatorname{Rp} 30 \\
25 \% \times \operatorname{Rp} 250.000 .000=\operatorname{Rp} 52 \\
30 \% \times \operatorname{Rp} 144.780 .000=\operatorname{Rp} 43\end{array}$ & $\begin{array}{l}=\operatorname{Rp} 2.500 .000 \\
.000 .000 \\
.500 .000 \\
.434 .000\end{array}$ \\
\hline $\begin{array}{l}\text { Jumlah PPH terutang } \\
\text { Kredit pajak } \\
\text { PPH } 25 \\
\text { PPH } 21 \text { istri }\end{array}$ & $\begin{array}{l}\text { Rp } 138.434 .000 \\
\text { Rp } 10.000 .000 \\
\text { Rp 26.968.000 }\end{array}$ \\
\hline $\begin{array}{l}\text { PPH kurangdibayar } \\
\text { Apabila tahun } 2019 \text { perhitungan } \\
\text { Penghasilan neto suami } \\
\text { Penghasilan neto istri }\end{array}$ & $\begin{array}{l}\text { Rp 101.466.000 } \\
\text { PPH sbg: } \\
\text { Rp 447.500.000 } \\
\text { Rp 231.600.000 }\end{array}$ \\
\hline $\begin{array}{l}\text { Jumlah penghasilan } \\
\text { PTKP }(\mathrm{k} / 1) \\
(24.300 .000+2.025 .000+2.02\end{array}$ & $\begin{aligned} \operatorname{Rp~679.450.000} \\
\text { Rp 52.650.000 } \\
5.000+24.300 .000)\end{aligned}$ \\
\hline $\begin{array}{l}\text { PKP } \\
\text { PPH terutang } \\
5 \% \times \operatorname{Rp} 50.000 .000 \\
15 \% \times \operatorname{Rp} 200.000 .000=\operatorname{Rp} 30 \\
25 \% \times \operatorname{Rp} 250.000 .000=\operatorname{Rp} 62 \\
30 \% \times \operatorname{Rp} 126.450 .000=\operatorname{Rp} 37\end{array}$ & $\begin{array}{l}\quad \mathrm{Rp52.650.000} \\
=\mathrm{Rp} 2.500 .000 \\
.000 .000 \\
.500 .000 \\
.935 .000\end{array}$ \\
\hline $\begin{array}{l}\text { Jumlah PPH terutang } \\
\text { Kredit pajak: } \\
\text { PPH pasal } 25 \\
\text { PPH pasal } 21 \text { istri } \\
\text { PPH yg kurang bayar thn } 2019\end{array}$ & $\begin{array}{l}\text { Rp 132.935.000 } \\
\text { Rp 10.000.000 } \\
\text { Rp 26.968.000 } \\
\text { Rp 95.967.000 }\end{array}$ \\
\hline
\end{tabular}

\section{E. SIMPULAN}

Berdasarkan hasil analisa perhitungan diatas apabila Wajib Pajak orang pribadi mempunyai usaha terlebih dahulu mengitung norma penghasilan Pajak neto nya seteah itu perhtungan Rekonsilasi Fiskal terhada Laporan Keuangan laba rugi, maka dapat ditarik kesimpulan sebagai berikut.

1. Wajib pajak orang pribadi yang mempunyai usaha terlebih dahulu membuat perhitngan norma pajak penghasila neto setelah itu membuat laporan rekonsilasi fiskal terhadap Laporan keuangan sesuai dengan peraturan perpajakan yang berlaku.

2.Wajib Pajak telah membuat perhitungan pajak penghasilan neto terhadap laporan 


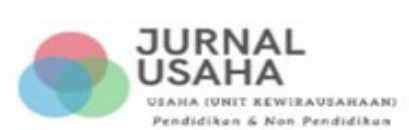

Vol 1, No. 1 (2020), June 2020

E-ISSN: 2746-2471

rekonsiliasi dalam rangka perhitungan Pajak Penghasilan terhutang sebesar Rp 132.935 .000

3 dalam perhitungan norma pajak penghasilan neto pada Wajib Pajak orang pribadi yang mempunyai usaha pada wilayah Kantor Pajak Prtama Pasar Minggu telah dilakukan sesuai tarif pajak yang berlaku berdasarkan peredaran bruto perusahaan dan dengan menggunakan laba bersih sebelum pajak menurut fiskal. 


\section{DAFTAR PUSTAKA}

Edy Supriyanto, Akutansi Perpajakan, Graha Ilmu. Jakarta 2015

Siti Resmi, Perpajakan, edisi revsi Penerbit Salemba Empat Jakarta 2019

Peraturan Direktur Jendral Pajak nomor PER-17/PJ/2015 tentang norma perhitungan penghasilan neto.

Undang Undang Nomor 16 tahun 2009 tentang perubahan tentang Ketentuan Umum dan Tata cara Perpajakan

Undang Undang Nomor 36 Tahun 2008 tentang Pajak Penghasilan

Analisis terhadap koreksi fiskal pajak penghasilan pada PT Bitung MinaUtama di kota Bitung Ryan C.C Languju, Jantje J. Tinangon, Inggriani Elim Vol 2, No 3 (2014)

https:/ejournal.unsrat.ac.id/index.php/emba/article/view/5782

Analisis Rekonsiliasi Fiskal atas laba rugi dalam penentuan pajak penghasilan ( PPh ) terutang Empud Syarifuddin, Toni Andrianto, Miftahudin Mifftahudin Vol 1, No 1 (2014) http://jurnal.stiekesatuan.ac.id/index.php/joma/article/view/795

Simulasi Penerapan Norma Dan Pembukuan Dalam Menghitung Pajak Penghasilan Orang Pribadi Pada Catering X Di Surabaya Dian Puspitosari (2016)

http://repository.unair.ac.id/215/ 